\title{
Article \\ Adhesion of Platelets to Colon Cancer Cells Is Necessary to Promote Tumor Development in Xenograft, Genetic and Inflammation Models
}

\author{
Marica Cariello ${ }^{1}$, Elena Piccinin ${ }^{1,2}{ }^{\oplus}$, Roberta Zerlotin ${ }^{1}$, Marilidia Piglionica ${ }^{1}$, Claudia Peres ${ }^{3}{ }^{\circledR}$, Chiara Divella ${ }^{4}$, \\ Anna Signorile ${ }^{2}$, Gaetano Villani ${ }^{2}$ (), Giuseppe Ingravallo ${ }^{5}$, , Carlo Sabbà ${ }^{1}$ and Antonio Moschetta ${ }^{1,3, *,+(1)}$ \\ 1 Department of Interdisciplinary Medicine, “Aldo Moro" University of Bari, 70124 Bari, Italy; \\ marica.cariello@uniba.it (M.C.); elena.piccinin@uniba.it (E.P.); roberta_zerlotin@libero.it (R.Z.); \\ marilidia.piglionica@uniba.it (M.P.); carlo.sabba@uniba.it (C.S.) \\ 2 Department of Basic Medical Sciences, Neurosciences and Sense Organs, "Aldo Moro" University of Bari, \\ 70124 Bari, Italy; anna.signorile@uniba.it (A.S.); gaetano.villani@uniba.it (G.V.) \\ 3 INBB, National Institute for Biostructures and Biosystems, 00136 Rome, Italy; claudiaperes18@gmail.com \\ 4 Nephrology, Dialysis, and Transplantation Unit, Department of Emergency and Organ Transplantation, \\ University of Bari Aldo Moro, 71024 Bari, Italy; claretta.divella@libero.it \\ 5 Pathology Section, Department of Emergency and Organ Transplantation, University of Bari Aldo Moro, \\ 70124 Bari, Italy; giuseppe.ingravallo@uniba.it \\ * Correspondence: antonio.moschetta@uniba.it; Tel.: +39-0805593262; Fax: +39-0805478126 \\ + Present address: Clinica Medica “Cesare Frugoni”, Department of Interdisciplinary Medicine, University of \\ Bari "Aldo Moro", Piazza Giulio Cesare 11, 70124 Bari, Italy.
}

\section{check for} updates

Citation: Cariello, M.; Piccinin, E.; Zerlotin, R.; Piglionica, M.; Peres, C.; Divella, C.; Signorile, A.; Villani, G.; Ingravallo, G.; Sabbà, C.; et al. Adhesion of Platelets to Colon Cancer Cells Is Necessary to Promote Tumor Development in Xenograft, Genetic and Inflammation Models. Cancers 2021, 13, 4243. https://doi.org/ $10.3390 /$ cancers 13164243

Academic Editor: Jennifer Black

Received: 6 July 2021

Accepted: 20 August 2021

Published: 23 August 2021

Publisher's Note: MDPI stays neutral with regard to jurisdictional claims in published maps and institutional affiliations.

Copyright: (c) 2021 by the authors. Licensee MDPI, Basel, Switzerland. This article is an open access article distributed under the terms and conditions of the Creative Commons Attribution (CC BY) license (https:// creativecommons.org/licenses/by/ $4.0 /)$.
Simple Summary: Platelets are small, anucleate, metabolically active cells and they represent an important linkage between tissue damage and inflammatory response. Several studies focused on the central role of platelets in inflammation and tumor development through their direct interaction with other cell types. Mice lacking the vascular adhesion molecules P-selectin exhibited a reduction in tumor metastases. We demonstrated that P-selectin-ablated platelets reduced tumor growth in a xenograft adenocarcinoma model. Furthermore, the lack of P-selectin decreased colon cancer progression in genetic mouse models and in chemically-induced colitis colorectal carcinogenesis. Our results suggest that platelets-cancer cells crosstalk via P-selectin is fundamental for tumor development.

Abstract: Platelets represent the linkage between tissue damage and inflammatory response with a putative role in tumorigenesis. Given the importance of the microenvironment in colon cancer development, we elucidated the eventual role of platelets-cancer cells crosstalk in in vivo colon cancer models. To evaluate the involvement of platelets in intestinal tumorigenesis, we first analyzed if the ablation of $\beta$-integrin P-selectin that drives platelets-cell adhesion, would contribute to plateletscolon cancer cell interaction and drive cancer progression. In a xenograft tumor model, we observed that when tumors are inoculated with platelets, the ablation of P-selectin significantly reduced tumor growth compared to control platelets. Furthermore, in genetic models, as well as in chronic colitisassociated colorectal carcinogenesis, P-selectin ablated mice displayed a significant reduction in tumor number and size compared to control mice. Taken together, our data highlights the importance of platelets in the tumor microenvironment for intestinal tumorigenesis. These results support the hypothesis that a strategy aimed to inhibit platelets adhesion to tumor cells are able to block tumor growth and could represent a novel therapeutic approach to colon cancer treatment.

Keywords: colon cancer; platelets; P-selectin

\section{Introduction}

The crosstalk between cancer cells and the microenvironment has a pivotal role in tumor development. Several studies focused on the involvement of platelets in cancer 
development and metastatization [1]. Platelets are produced from megakaryocytes in the bone marrow and are key regulators of hemostasis, repair and inflammation [2]. Platelets are anucleate, metabolically active cells provided with endoplasmic reticulum, Golgi apparatus, mitochondria and granules [3], and they are able to translate mRNAs into proteins $[4,5]$. Platelets can affect tumor growth and metastasis via several mechanisms, including the release of growth factors and cytokines, such as TGF- $\beta$, PDGF [6] and proinflammatory lipid signaling via PAF [7], the enhancement of the adhesion of cancer cells to the endothelium and the direct interaction with cancer cells. Specifically, platelet aggregates can prevent tumor cell death, creating a physical shield around tumor cells that protects them from natural killer cell-mediated death facilitating tumor cell dissemination into the bloodstream [8,9]. Moreover, Labelle et al. demonstrated that the platelets-colon cancer cells crosstalk and the production of TGF- $\beta$ promote metastasis formation in the lung by inducing the epithelial-mesenchymal like transition (EMT) [10]. At the same time, cancer cells can assimilate platelet-derived proteins (platelets mimicry), enhancing the hematogenous dissemination of tumors [11].

P-selectin (CD62P) belongs to the selectin family and it is a cell adhesion molecule stored on platelets $\alpha$-granules and Weibel-Palade bodies [12]. After inflammatory or thrombogenic stimuli, P-selectin translocates on the membrane surface mediating transient platelets contact with vascular endothelial cells [13]. Alves et al. observed that CD44 on LS174T colon cancer cells is the functional ligand of platelets P-selectin [14]. Several studies have shown that P-selectin deficient mice displayed a lower number of metastatic cells compared to wild-type mice $[15,16]$. Mice injected with colon cancer cells without P-selectin ligands presented a strong reduction of tumor metastases. Moreover, in human cancer cell lines, it has been demonstrated that P-selectin mediated the platelets' adhesion to cancer cells [17], highlighting the key role of P-selectin in platelets cancer-cells crosstalk.

In the present work, we elucidated the eventual role of platelets-cancer cells crosstalk in in vivo models of colon cancer. In order to evaluate the involvement of platelets in intestinal tumorigenesis, we analyzed if the ablation of P-selectin would contribute to platelets-colon cancer cell interaction and reduce colon cancer progression.

\section{Results}

\subsection{Platelets-Intestinal Cells Crosstalk in Human Intestine}

To evaluate the platelets-colon cancer cells crosstalk, we analyzed human colon adenocarcinoma, normal ileum and normal colon by H\&E (Figure 1A). We assayed by P-selectin and CD41 (platelets marker) immunofluorescence human colon adenocarcinoma together with ileum and colon from control subjects. In normal ileum and colon, we observed the presence of platelets in close proximity to intestinal cells, whereas in adenocarcinoma platelets, aggregates along the intestinal epithelium, thus indicating the strong presence of platelets in the tumor microenvironment and the platelets-intestinal cells crosstalk in cancer (Figure 1B,C). In order to observe platelets-cancer cells crosstalk we performed CD44-P-selectin immunofluorescence in human healthy colon and colon adenocarcinoma. In normal colon we observed the expression of CD44 in colon cells and the presence of platelets (marked with P-selectin) in close proximity to cells. In adenocarcinoma, we detected platelets aggregates along the intestinal epithelium and a co-localization of CD44/Pselectin, thus indicating the strong presence of platelets in the tumor microenvironment and the platelets-intestinal cells crosstalk in cancer (Figure 1D, Supplementary Figure S1). 

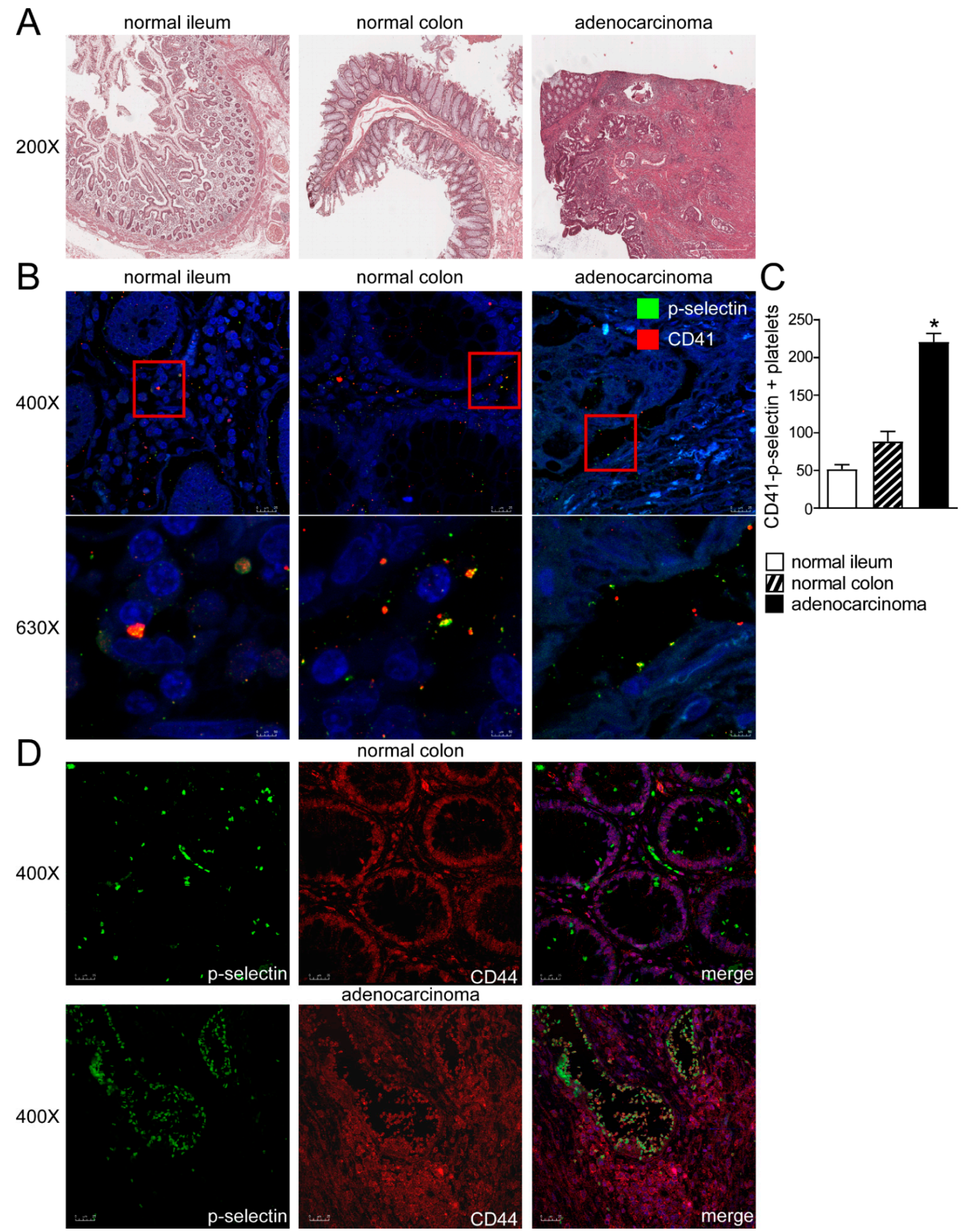

Figure 1. Platelets-intestinal cells crosstalk in human intestine. (A) Histology was assessed by H\&E staining and was observed by light microscopy (magnification, $200 \times$ ) in normal ileum, colon and colon adenocarcinoma. Representative specimens are shown. (B) The protein expression of P-selectin and CD41 was investigated by immunofluorescence and confocal microscopy analysis in paraffin-embedded sections from normal portions of ileum and colon and colon adenocarcinoma. P-selectin in green and CD41 in red. Representative images are shown. Magnification $630 \times$. (C) CD-41/Pselectin positive platelets were quantified by ImageJ software. Results are expressed as mean \pm SEM $\left({ }^{*} p<0.05\right)$. (D) The protein expression of P-selectin and CD44 was investigated by immunofluorescence and confocal microscopy analysis in paraffin-embedded sections from normal portions of colon and colon adenocarcinoma. P-selectin in green and CD44 in red. Representative images are shown. Magnification $400 \times$. 


\subsection{Platelets Isolated from P-selectin KO Mice Reduce Tumor Growth in Xenograft Adenocarcinoma Model}

In order to evaluate the tumor-promoting role exerted by platelets in CRC cells and the role of P-selectin in platelets-cancer cells crosstalk, we used a xenograft tumor model. Specifically, an HT-29 cell suspension was subcutaneously injected into the subscapular region of an athymic $(\mathrm{nu} / \mathrm{nu})$ mouse. Subsequently, a wild-type or P-selectin KO platelets suspension was directly injected into the tumor-bearing mice in each group every 7 days for a total of three injections per mouse over a time frame of 21 days. The tumor growth curves revealed a significant delay in the expansion of tumors treated with platelets isolated from the P-selectin KO mice (Figure 2A,B). In addition, as shown in Figure 2A,D, the injection of $\mathrm{P}$-selectin $\mathrm{KO}$ platelets significantly reduced the tumor weight compared to the control group.

Furthermore, we evaluated the expression of CD44 (P-selectin receptor) in HT-29 cells and the presence of platelets in xenograft tumors. HT-29 cells treated with P-selectin KO or control platelets exhibited CD44 protein expression (Figure 2E). We observed that in tumors treated with platelets isolated from the control mice, there were several platelets linked to HT-29 cells compared to tumors treated with P-selectin KO platelets, where the absence of P-selectin marked platelets are observed, as expected (Figure 2F). These data support the role of P-selectin in the direct platelets-cancer cells crosstalk and the relevance of the interaction between platelets and colon cancer cells in intestinal tumorigenesis.

To explore the mechanisms underlying platelets mediated colon cancer cells' proliferation, we examined if any alteration of cell cycle occurred, by analyzing the regulators of cell cycle progression (CyclinD1, CyclinE1 (Ccne1) and proliferating cell nuclear antigen (Pcna) and the tumor suppressor Pten (phosphatase and tensin homolog deleted on chromosome ten), which is frequently modified in human cancers, including breast, lung, prostate and bladder cancer [18]. In a xenograft tumor model, we observed a trend of reduction of the CyclinD1 and Pcna gene expression levels in HT-29 cells treated with P-selectin KO platelets compared to HT-29 cells treated with control platelets (Supplementary Figure S2). In this model, treatment with P-selectin $\mathrm{KO}$ platelets significantly changed cyclinD1 and Pcna protein accumulations, as well as Ccne1 and Pten gene expression compared to treatment with control platelets (Figure $3 \mathrm{~A}-\mathrm{C}$ ). Furthermore, we analyzed the expression of Il6, a marker of inflammation, finding a significant downregulation of Il-6 gene expression levels in tumors treated with platelets isolated from the P-selectin $\mathrm{KO}$ mice compared to tumors treated with platelets isolated from the control mice (Figure 3C).

\subsection{Lack of P-selectin Protects from Intestinal Carcinogenesis in Genetic Mouse Model of Tumor}

To address the tumor-promoting role of P-selectin in colon cancer, we used a genetic model of intestinal tumor formation. We crossed $\mathrm{APC}^{\mathrm{Min} /+}$ with P-sel ${ }^{-/-}$or control mice to obtain a new genetic mouse model in which the lack of P-selectin occurred in mice that spontaneously developed tumors. The $\mathrm{APC}^{\mathrm{Min}} / \mathrm{P}-\mathrm{sel}^{-/-}$mice exhibited a significant decrease in tumor number compared to the $\mathrm{APC}^{\mathrm{Min} /+}$ mice (Figure $\left.4 \mathrm{~A}\right)$. The histological examination (H\&E) of the $\mathrm{APC}$ Min $/ \mathrm{P}_{-} \mathrm{sel}^{-/-}$mice intestine displayed a more preserved parenchyma than the $\mathrm{APC}^{\mathrm{Min} /+}$ mice, whereas a disrupted intestinal structure was detected in the $\mathrm{APC}^{\mathrm{Min} /+}$ mice (Figure 4B). Furthermore, in the $\mathrm{APC}^{\mathrm{Min}} / \mathrm{P}-\mathrm{sel}^{-/-}$mice we observed a significant reduction in cyclinD1 and Pcna protein levels compared to the $\mathrm{APC}^{\mathrm{Min} /+}$ mice (Figure 4C-F). In the APC ${ }^{\mathrm{Min}} / \mathrm{P}_{-} \mathrm{sel}^{-/-}$mice, we did not find a significant difference in Pten and Il6 gene expression levels and we detected a reduction in c-myc and Ccne1 gene expression levels compared to the APC ${ }^{\mathrm{Min} /+}$ mice (Supplementary Figure S3, Figure 4G), highlighting that the absence of P-selectin reduces tumor growth after pro-carcinogenic events. All together, these data point to the importance of platelets in tumor induction and progression in genetic, non-inflammatory models. 


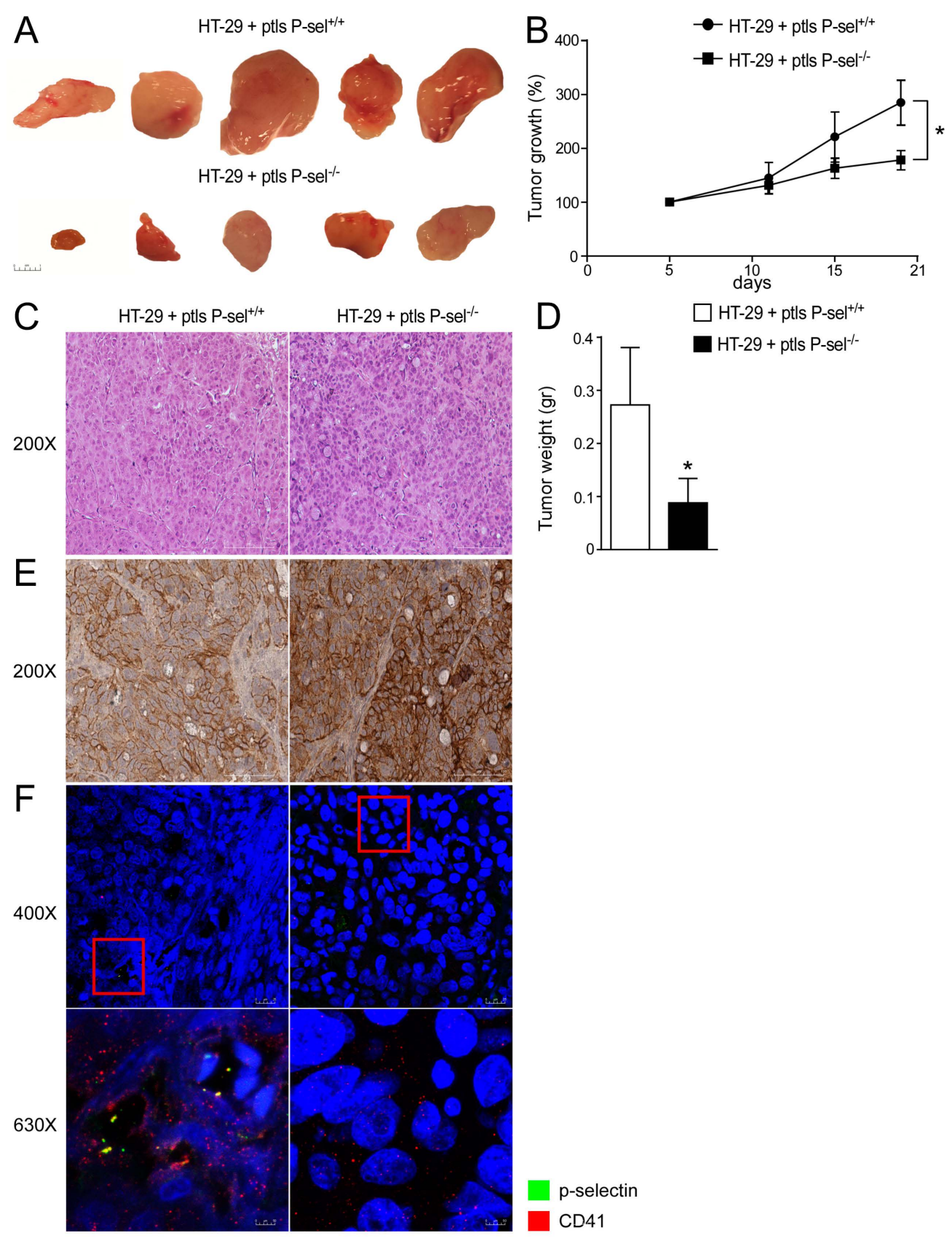

Figure 2. P-selectin $\mathrm{KO}$ platelets injection reduced tumor growth in xenograft tumor model. (A) Athymic nu/nu mice were injected subcutaneously with HT29 cells and platelets isolated from ${\mathrm{P}-\mathrm{sel}^{-/-}}^{-}$and P-sel ${ }^{+/+}$mice were administered directly into the tumor mass every 7 days. Gross morphology of HT-29 cells treated with P-sel ${ }^{+/+}$platelets and HT-29 cells treated with $\mathrm{P}-\mathrm{sel}^{-/-}$. (B) Tumor growth (\%) curves showed a reduction in the expansion of tumors injected with P-sel $^{-/-}$platelets ( $n=10$ mice per group). (C) Histology was assessed by H\&E staining and was observed by light microscopy (magnification, $200 \times$ ). Representative specimens are shown. (D) Tumor weight (gr) was reported. The results are expressed as mean $\pm \mathrm{SEM}, n=20$ tumors per group; ${ }^{*} p \leq 0.05$. (E) Paraffin-embedded tumor specimens from HT-29 cells treated with P-sel ${ }^{+/+}$platelets and HT-29 cells treated with P-sel ${ }^{-/-}$platelets were immunoassayed with CD44 antibody (200× magnification). Representative specimens are shown. (F) The protein expression of P-selectin and CD41 was investigated by immunofluorescence and confocal microscopy analysis in paraffin-embedded sections from tumors injected with $\mathrm{P}_{-} \mathrm{sel}^{-/-}$or control platelets. P-selectin in green and CD41 in red. Representative images are shown. Magnification $630 \times$. 


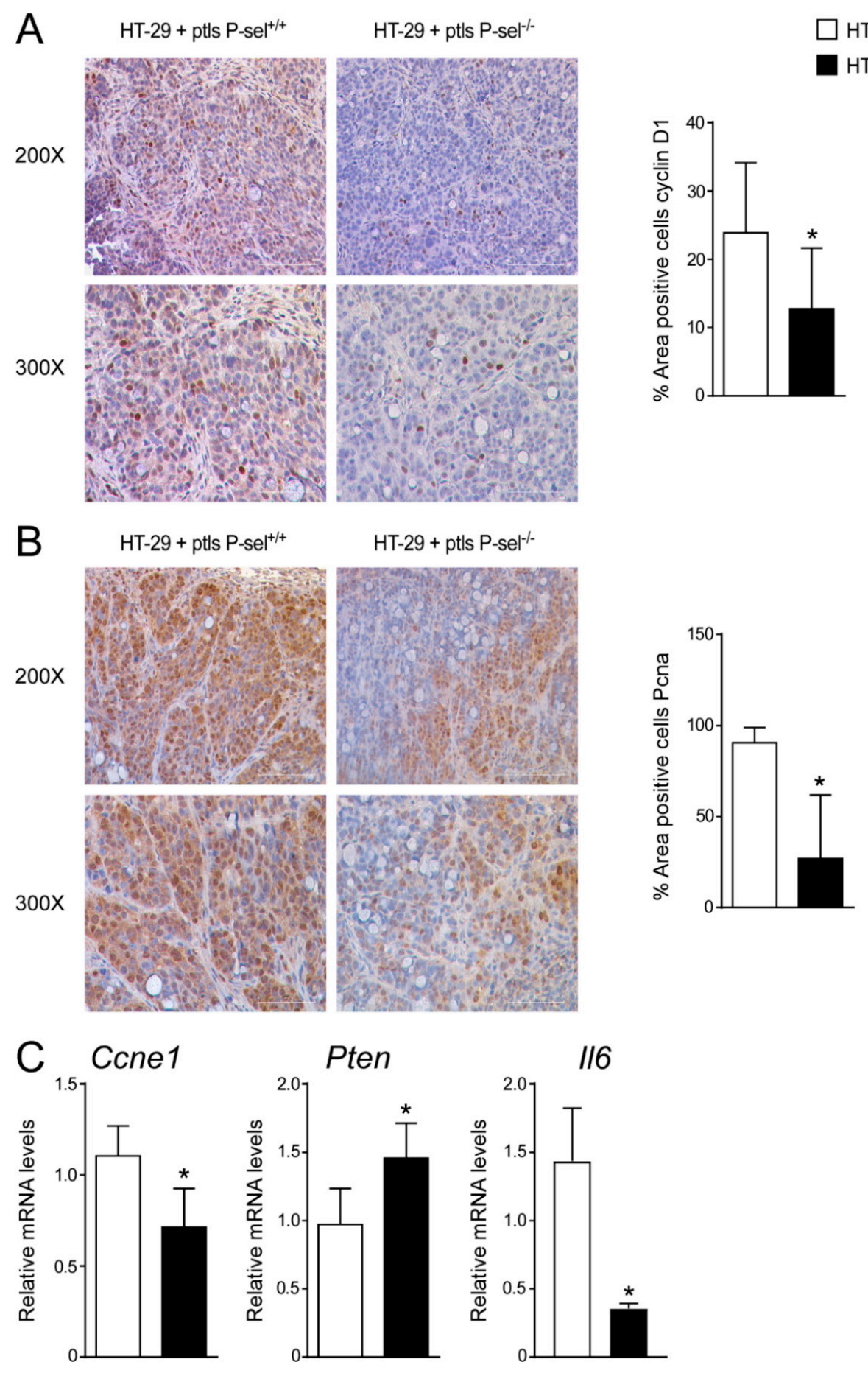

Figure 3. Treatment with P-selectin KO platelets reduced cell cycle progression in xenograft tumor model. Paraffinembedded tumor specimens from HT-29 cells treated with P-sel ${ }^{+/+}$platelets and HT-29 cells treated with P-sel ${ }^{-/-}$platelets $^{-}$ were immunoassayed with (A) cyclin D1 antibody (200× and 300 $\times$ magnification) and (B) anti-Pcna antibody (200 $\times$ and $300 \times$ magnification). Representative specimens are shown. Cyclin D1 and Pcna staining per field was quantified by ImageJ software and reported as percentage per field. Comparison of HT-29 cells treated with P-sel ${ }^{+/+}$platelets and HT-29 cells treated with $\mathrm{P}_{-} \mathrm{sel}^{-/-}$platelets ( $n=8$ /group) was performed using the Student's t-test. Results are expressed as mean \pm SEM ( $\left.{ }^{*} p<0.05\right)$. (C) Gene expression analysis of Ccne1, Pten and Il6 in HT-29 cells treated with P-sel ${ }^{+/+}$platelets and HT-29 cells treated with $\mathrm{P}_{-} \mathrm{sel}^{-/-}$platelets ( $n=20$ tumors per group). Cyclophilin was used as a housekeeping gene to normalize data. The results are expressed as mean \pm SEM. Statistical significance $\left({ }^{*} p<0.05\right)$ was assessed by the Student's $t$-test. 


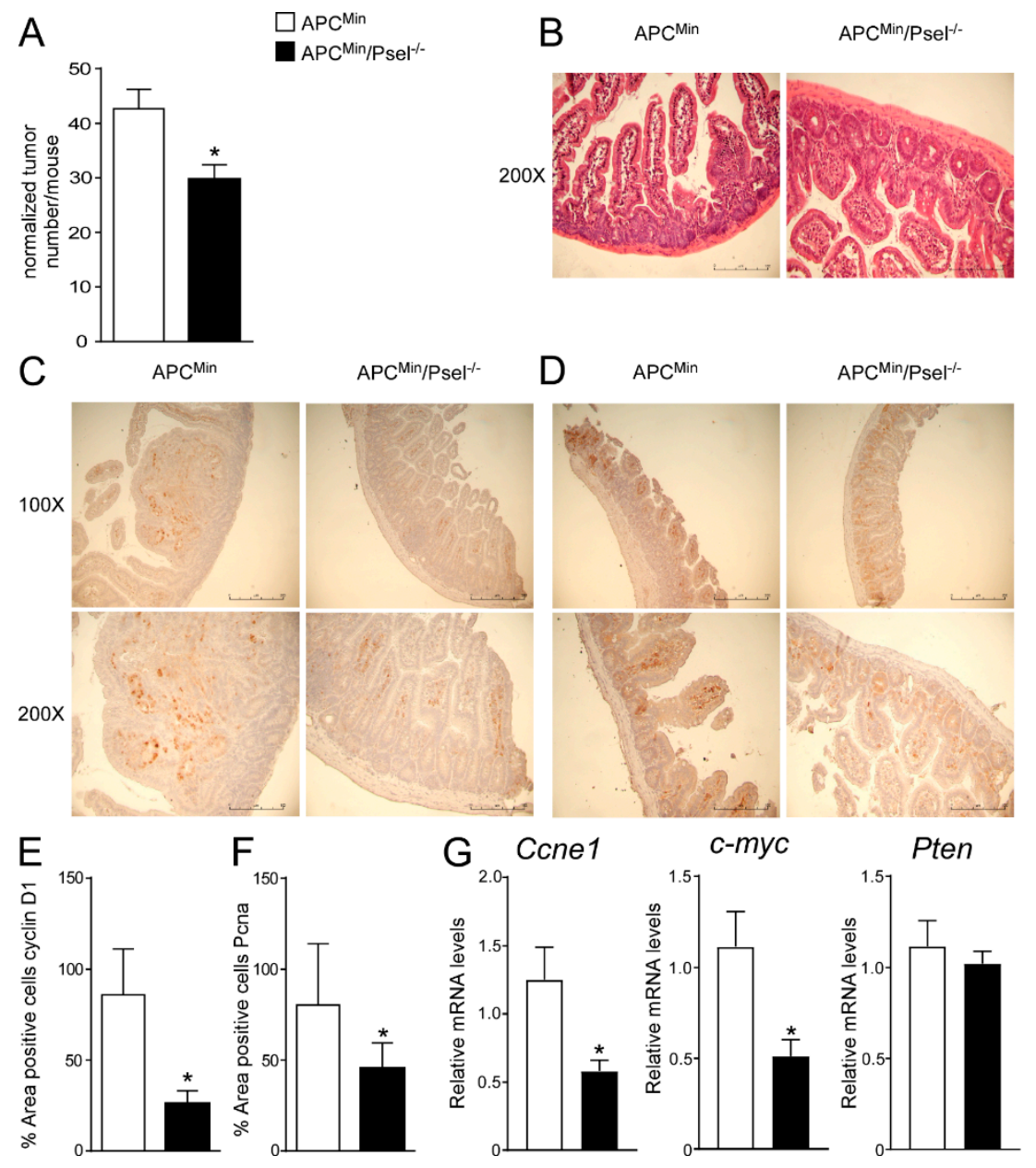

Figure 4. Role of P-selectin in genetic mouse model of colon cancer. (A) Total number of tumors was counted in $\mathrm{APC}^{\mathrm{Min}} / \mathrm{P}_{-} \mathrm{sel}^{-/-}$and $\mathrm{APC}^{\mathrm{Min}}$ mice. Results are the average \pm standard error of the mean (SEM), $n=10$ mice per group; ${ }^{*} p \leq 0.05$. (B) Histology was assessed by H\&E staining and was observed by light microscopy (magnification, $200 \times$ ). Representative specimens are shown. Paraffinembedded tumor specimens from $\mathrm{APC}{ }^{\mathrm{Min}} / \mathrm{P}_{-} \mathrm{sel}^{-/-}$and $\mathrm{APC}{ }^{\mathrm{Min}}$ mice were immunoassayed with (C) cyclin D1 antibody (100× and 200× magnification) and (D) anti-Pcna antibody (100× and 200× magnification). Representative specimens are shown. (E) Cyclin D1 and (F) Pcna staining per field was quantified by ImageJ software and reported as percentage per field. To perform protein quantification 10 representative images were taken with a $200 \times$ magnification for each sample. The percentage of stained area/total area was measured. Values from all consecutive images for each sample were averaged. Comparison of tumor specimens from $\mathrm{APC} \mathrm{Min}^{\mathrm{P}} \mathrm{P}-\mathrm{sel}^{-/-}$and $\mathrm{APC}$ Min mice was performed using T student's test ( $n=5$ mice per group). Results are expressed as mean $\pm \mathrm{SEM}$ $\left({ }^{*} p<0.05\right)$. (G) Gene expression analysis of Ccne1, c-myc and Pten in APC ${ }^{\mathrm{Min}} / \mathrm{P}-\mathrm{sel}^{-/-}$and APC ${ }^{\mathrm{Min}}$ mice. Cyclophilin was used as a housekeeping gene to normalize data. The results are expressed as mean \pm SEM. Statistical significance $\left({ }^{*} p<0.05\right)$ was assessed by the Student's $t$-test $(n=10$ mice per group).

\subsection{P-selectin KO Mice Are Protected from Chronic Colitis-Associated Colorectal Carcinogenesis}

In order to address the tumor-promoting role of P-selectin also in inflammatory models of colon cancer, we subjected P-selectin $\mathrm{KO}$ and the control wild-type (C57J/Bl6) mice to a model of chemically-induced colitis carcinogenesis [19]. To induce tumor formation, an intraperitoneal azoxymethane (AOM) injection was followed by three cycles of dextran sulfate sodium (DSS) treatment, as shown in Figure 5A. The P-selectin KO mice displayed a significant reduction in total tumor number and size with respect to the wild-type group (Figure $5 \mathrm{~B})$. The number of big $(>5 \mathrm{~mm})$ and small $(<5 \mathrm{~mm})$ tumors was significantly 
reduced in the P-selectin KO mice compared to the control mice (Figure 5B). C-myc overexpression is a fundamental oncogenic mechanism in several cancers, including colon cancer $[20,21]$. In the P-selectin KO mice we did not find significant difference in Cyclin D1, Ccne1, Pten, Pcna and Il6 gene expression levels (Supplementary Figure S4) and we showed a reduction of c-myc gene expression compared to the control mice (Figure 5C). These data confirm the relevance of platelets in the tumor microenvironment and the prominent role of P-selectin to direct platelets-cancer cells crosstalk also in inflammation-induced colorectal tumorigenesis.
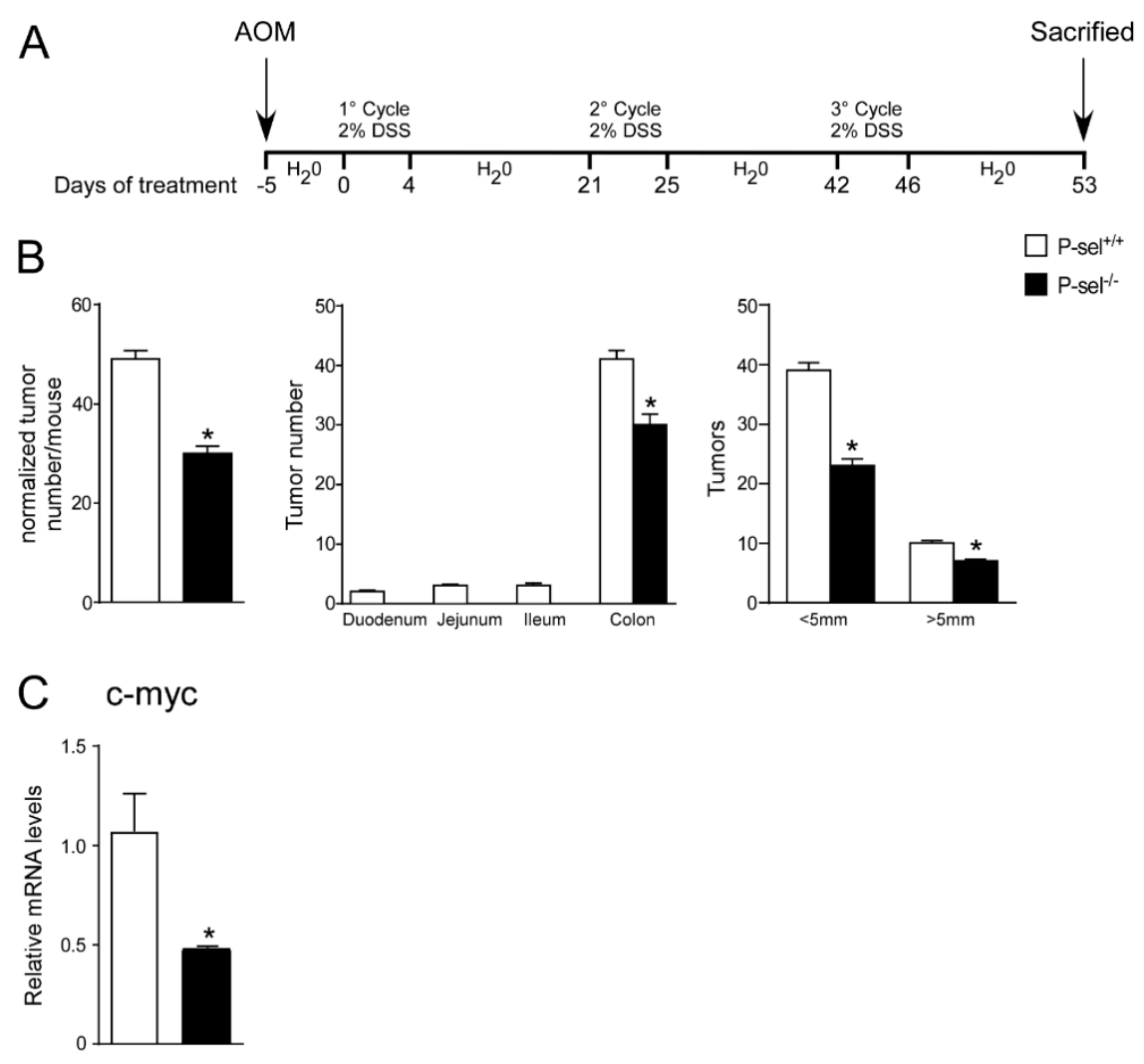

Figure 5. P-selectin $\mathrm{KO}$ mice are protected from chronic colitis-associated colorectal carcinogenesis. (A) P-sel ${ }^{-/-}(n=10)$ and P-sel ${ }^{+/+}$(wild-type; $\left.n=10\right)$ mice were treated for a colitis-associated colorectal carcinogenesis model through one intraperitoneal azoxymethane (AOM) injection and 3 cycles of $2 \%$ dextran sulfate sodium (DSS) in drinking water. (B) Total number of tumors was counted. The diameter of each tumor was measured. The number of tumors with a diameter $<5 \mathrm{~mm}$ and $>5 \mathrm{~mm}$ was significantly reduced in $\mathrm{P}-\mathrm{sel}^{-/-}$mice showing that these mice are protected from colon cancer formation. Results are the average \pm standard error of the mean (SEM); ${ }^{*} p \leq 0.05$ (C) Gene expression analysis of c-myc in $\mathrm{P}_{-} \mathrm{sel}^{-/-}$and $\mathrm{P}_{-} \mathrm{sel}^{+/+}$mice. Cyclophilin was used as a housekeeping gene to normalize data. The results are expressed as mean $\pm \mathrm{SEM},{ }^{*} p \leq 0.05$.

\section{Discussion}

The present study evaluated the relevance of platelets in the microenvironment of colorectal tumors and the prominent role of P-selectin to direct platelets-cancer cells crosstalk. First, we showed in the xenograft tumor model of colon cancer that at the variance of control platelets when P-selectin ablated platelets were inoculated in HT-29 tumors, they were not able to induce tumor growth. Furthermore, we demonstrated that the lack of P-selectin decreased tumor growth in genetic mouse models and in chemically-induced colitis colorectal carcinogenesis.

The tumor microenvironment plays a pivotal role to modulate the ability of cancer cells to proliferate, to access the vasculature and to metastasize [22]. It has been shown that pharmacological or genetic depletion of blood platelets reduced tumor metastasis forma- 
tion $[23,24]$. Interestingly, in a cardiovascular prevention trial, Rothwell et al. observed that patients taking aspirin at doses sufficient to block platelets function showed a reduced risk for cancer metastasis [25]. Several studies demonstrated that platelets promote metastasis via different mechanisms, such as the generation of platelets aggregates, the adhesion of cancer cells to the endothelium, the promotion of tumor vascularization and the tumor cell migration into the bloodstream [26,27]. Guillem-Llobat et al. observed that human platelets co-cultured with human colon carcinoma cells HT-29 promoted EMT contributing to the metastasis formation [28]. Furthermore, in HT-29 cells, platelets-cancer cells' direct interaction induced COX-2-dependent PGE2 production leading to the regulation of p21 and cyclin B1 gene expression and the EMT promotion [27]. In the lungs, it has been shown that the contact between cancer cells and platelets is fundamental to induce pro-metastatic gene expression, EMT-like transformation and extravasation [10]. The open questions are the type of platelets-cancer cells' interaction in colon cancer induction and/or development.

Recently, in colitis-associated cancer, it has been observed that platelets represent a source of serum amyloid A that promotes myeloid cell-dependent immunosuppression leading to cancer development [29]. In the present work, we focused on CRC, a solid tumor closely related to platelets activities. Clinical studies and meta-analysis of randomized clinical trials have demonstrated that the administration of low-doses of aspirin, able to inhibit platelets function, decreased the risk of developing esophagus, stomach and colon cancers $[25,30,31]$. In chronic colitis-associated colorectal carcinogenesis, as well as in xenograft adenocarcinoma and in the genetic mouse model of CRC, we observed the crosstalk between platelets and colon cancer cells and we underscored the pivotal role of P-selectin in orchestrating this contact. P-selectin has been suggested as an important molecule for the adhesion of cancer cells [32]. At the same time, CD24, the P-selectin ligand, has been found in several human carcinomas [33,34]. Furthermore, CD44, another P-selectin ligand, has been shown in several colon cancer studies [14,28,35]. Guillem-Llobat et al. observed that coculturing HT-29 cells with human platelets promoted the mesenchymal-like cancer cells transition, cell mobility and proaggregatory action on platelets [28]. Alves et al. demonstrated the role of CD44 as a functional P-selectin ligand in colon adenocarcinoma cells [14]. Moreover, Hanley et al., through microbeads coated with CD44 immunoprecipitated from carcinomas, observed that variant isoforms of CD44 retained P-selectin binding activity [35]. In in vitro models of adenocarcinoma, P-selectin binding to cancer cells promoted their adhesion to fibronectin through the activation of p38MAPK and PI3-K signaling [36]. Moreover, Korniluk et al. observed a correlation between soluble P-selectin levels and the progression of CRC and the highest concentration of soluble P-selectin in patients with CRC and liver metastasis [37]. P-selectin KO mice injected with LS180 colon cells showed a reduction in tumor growth rate and in lung metastasis formation, suggesting that the P-selectin $\mathrm{KO}$ mice platelets did not adhere to tumor-cell surface receptors [16]. In a model of lung colony formation, it has been observed that thromboxane A2 receptor signaling enhanced tumor colonization via P-selectin-mediated platelets-cancer cells crosstalk [38]. Moreover, in insulinoma and CRC mouse models, P-selectin deletion and soluble P-selectin blocked platelets deposition within tumors and the secretion of VEGF, leading to the reduction of angiogenesis and tumor growth $[39,40]$. Recently, Wang et al. demonstrated that platelets expressing P-selectin enhance the ability of bone-marrow mesenchymal stem cells (BM-MSCs) to promote cancer metastasis. The supernatants of the BM-MSCs, when stimulated by platelets, enhance the expression of c-Myc in gastric tumor cells [41]. Furthermore, Mitrugno A. and colleagues demonstrated that in cancer cell lines (SW480 and PANC-1) proliferation was enhanced through human platelets via the upregulation and activation of c-myc. The ability of platelets to promote c-myc expression and cancer cell proliferation was reverted by aspirin [42]. Based on these recent data, it is conceivable that platelets-cancer cell interaction via P-selectin induces c-myc expression in cancer cells to promote cancer proliferation. Hence, the absence of P-selectin or the use of aspirin that reduces platelets activation and function inhibits platelet cancer cells crosstalk reducing tumor development. 
Potential limitations of our study need to be appreciated. We conducted the experiment with human samples with a small number of participants. A xenograft mouse model was performed with platelets isolated from the P-selectin $\mathrm{KO}$ mice and wild-type using a single colon cancer HT-29 cell line.

In the present study, we found that P-selectin deficiency inhibited the direct interaction between platelets and colon cancer cells, thus reducing tumor growth by modulating the expression of genes involved in cell cycle progression, such as CyclinD1, Ccne1 and Pcna. Interestingly, both in the genetic mouse model (APC ${ }^{\mathrm{Min}} / \mathrm{P}-\mathrm{sel}^{-/-}$mice) and in the inflammation-dependent cancer development model (AOM/DSS), we observed that the deletion of P-selectin inhibited tumor development mediating platelet adhesion to tumor cells. Furthermore, using P-selectin KO mice models and injecting platelet suspension directly into the tumor-bearing mice, we confirmed that platelets-cancer cells' interaction has a pivotal role in cancer promotion and that platelets' adhesion to cancer cells via P-selectin is necessary for the observed phenotype.

\section{Material and Methods}

\subsection{Mice}

Adenomatous polyposis coli $\mathrm{APC}^{\mathrm{Min} /+} / \mathrm{P}-\mathrm{sel}^{-/-}$mice were generated by crossing pure strain $\mathrm{APC}^{\mathrm{Min} /+}$ mice obtained from The Jackson Laboratory (Bar Harbor, ME, USA) with pure strain C57B6J/P-selectin ${ }^{-/-}$mice kindly provided by Dr V. Evangelista (Chieti, Italy). All mice were housed under pathogen-free conditions in a temperature-controlled room $\left(23^{\circ} \mathrm{C}\right)$ on a $12 \mathrm{~h}$ light/dark cycle and fed a standard rodent chow diet and water ad libitum.

\subsection{Patients}

We obtained tissue (tumors and normal intestinal mucosa) samples from the Pathology Section of Department of Emergency and Organ Transplantation (University of Bari, Bari, Italy). Six patients with colon adenocarcinoma and 4 control subjects were recruited for a previous study after approval by the Ethical Committee of the Azienda OspedalieroUniversitaria Policlinico of Bari, Italy. The baseline characteristics of subjects are described in Table 1. All subjects gave their written informed consent for the use of clinical data and samples for scientific research purposes.

Table 1. Clinical characterization of the study population. Data are presented as mean \pm SEM (standard error of the mean).

\begin{tabular}{lll}
\hline Clinical Variable & Control & Colon Adenocarcinoma \\
\hline$n(\mathrm{M}: \mathrm{F})$ & $4(2: 2)$ & $6(4: 2)$ \\
Age (year) & $54.8 \pm 9.5$ & $60.1 \pm 10.1$ \\
Pathological staging & - & $\mathrm{T} 3 / \mathrm{T} 4$ \\
Lymph node status & - & $\mathrm{N} 0 / \mathrm{N} 2$ \\
\hline
\end{tabular}

\subsection{Platelets Isolation}

The platelets were isolated from C57B6J or P-selectin ${ }^{-/-}$mice whole blood and anti-coagulated with sodium citrate $3.8 \%$. Platelet-rich plasma (PRP) was prepared by centrifugation of citrated blood at $200 \mathrm{~g}$ for $20 \mathrm{~min}$. Platelets were washed with prostaglandin E1 (PGE1) (Sigma, Italy) and resuspended in an ice-cold, HEPES-Tyrode buffer (pH 7.4) containing $129 \mathrm{mM} \mathrm{NaCl}, 8.9 \mathrm{mM} \mathrm{NaHCO}_{3}, 2.8 \mathrm{mM} \mathrm{KCl}, 0.8 \mathrm{mM} \mathrm{KH}_{2} \mathrm{PO}_{4}, 56 \mathrm{mM}$ dextrose, $10 \mathrm{mM}$ HEPES. Immediately before platelet injection, $1 \mathrm{mmol} / \mathrm{L} \mathrm{MgCl} 2,1 \mathrm{mmol} / \mathrm{L} \mathrm{CaCl}_{2}$ and RGD peptide (GRGDNP) (Sigma, Italy) were added to the cells [43].

\subsection{Xenograft Mouse Model}

A colorectal cell suspension $\left(100 \mu \mathrm{L} ; 1 \times 10^{7}\right.$ HT29 cells from American Type Culture Collection, Manassas, VA, USA) was injected subcutaneously into the subscapular region 
of an athymic CD1 mice (The Jackson Laboratory, Bar Harbor, ME, USA) as previously described [44]. The animals were treated with platelets isolated from P-selectin ${ }^{-/-}$or wildtype mice directly injected into the tumor. For xenograft treated with mouse platelets, mice were divided randomly into 2 groups, each group containing 10 mice (i.e., 20 tumors) as follows: P-selectin ${ }^{-/-}$platelets group and P-selectin ${ }^{+/+}$platelets group (control group). Subsequently, $100 \mu \mathrm{L}$ of platelets suspension $\left(10^{6}\right.$ platelets) was injected with a 27 -gauge needle directly into the tumor-bearing mice in each group every 7 days for a total of 3 injections per mouse. Tumor growth was measured as follows: long diameter (a) and short diameter (b) were measured using a digital vernier caliper, and volumes $(\mathrm{V})$ of the tumors were calculated according to the formula $V=\frac{1}{2} \cdot a \cdot b^{2}$, and a tumor growth curve was drawn. Tumor weight (gr) was measured using a calibrated analytical balance. All the mice then were sacrificed and tumors were harvested for further analysis.

\subsection{Colitis Carcinogenesis Model}

For the chemically-induced colitis carcinogenesis model [19], 20 pathogen-free, 16-week-old male C57B6J $(n=10)$ and P-selectin ${ }^{-/-}(n=10)$ mice were injected intraperitoneally with $12 \mathrm{mg} / \mathrm{kg}$ body weight of AOM dissolved in $0.9 \% \mathrm{NaCl}$. Five days later, $3 \%$ DSS was given in the drinking water over 5 days, followed by 16 days of regular water. This cycle was repeated 3 times and body weight was measured at the end of each cycle.

\subsection{RNA Extraction}

Total RNA was isolated by a Qiazol reagent (Qiagen) following the manufacturer's instructions. To avoid possible DNA contaminations, the RNA was treated with DNase I (Thermo Fisher Scientific). RNA purity was checked by spectrophotometer and RNA integrity by examination on agarose gel electrophoresis. cDNA was synthesized retrotranscribing $4 \mu \mathrm{g}$ of total RNA in a total volume of $100 \mu \mathrm{L}$ using a High Capacity DNA Archive Kit (Thermo Fisher Scientific) following the manufacturer's instructions.

\subsection{Real-Time Quantitative PCR}

qPCR assays were conducted in triplicate wells for each sample. Baseline values of amplification plots were set automatically, and threshold values were kept constant to obtain normalized cycle times and linear regression data. The reaction mixture per well used were as follows: 10 AL Power Syber Green (Thermo Fisher Scientific), 2.4 AL of primers at the final concentration of $150 \mathrm{nmol} / \mathrm{L}$, 4.6 AL RNAase free water, and 3 AL cDNA (60 ng). For all experiments, PCR conditions used were as follows: denaturation at $95{ }^{\circ} \mathrm{C}$ for $10 \mathrm{~min}$, followed by 40 cycles at $95{ }^{\circ} \mathrm{C}$ for $15 \mathrm{~s}$, then at $60{ }^{\circ} \mathrm{C}$ for $60 \mathrm{~s}$. Quantitative normalization of cDNA in each sample was performed using cyclophilin as an internal control. Validated primer sequences for RTqPCR are: Cyclin E1 FW GACCCACAGAGACAGCTTGGA; RV GTTCAGACAAACATGGCTTTCTTTG; c-myc FW TGTATGTGGAGCGGTTTCTCA; RV CTGGTAGGAGGCCAGCTTCT; Il6 FW ATGCTTCCAATCTGGATTCAATG; RV CTCAAACTCCAAAAGACCAGTGATG; cyclophilin A FW CCTTCACTTTGCCAAACACCAC; RV CATCTGCACTGCCAAGACTGAG; cyclophilin B FW GGCCAACGATAAGAAGAAGGG; RV ACAAAATTATCCACTGTTTTTGGAACA. For Pten RTqPCR we used an IDT validated primer (code Hs.PT.53.26587300). PCR assays were performed in 96-well optical reaction plates using the QuantStudio5 machine (Thermo Fisher Scientific). All reactions were run in triplicate. Relative quantification was conducted using the $\Delta \Delta C T$ method.

\subsection{Histology and Immunohistochemistry}

Tissue specimens were fixed in $10 \%$ formalin for 12 to $24 \mathrm{~h}$, dehydrated, and paraffin embedded. Four $\mu \mathrm{m}$ thick sections were stained with hematoxylin-eosin (H\&E) following standard protocols. The sections were subjected to antigen retrieval by boiling the slides in sodium citrate $\mathrm{pH} 6$ (Sigma Aldrich, Milan, Italy) for $15 \mathrm{~min}$. The sections were permeabilized in a phosphate-buffered saline (PBS) with $0.25 \%$ TritonX-100 for $5 \mathrm{~min}$ 
and were sequentially incubated for $10 \mathrm{~min}$ at room temperature in a protein blocking solution (Dako, Glostrup, Denmark) and overnight at $4{ }^{\circ} \mathrm{C}$ with the primary antibodies (anti-Pcna, sc-7907, Santa Cruz Biotechnology, Santa Cruz, CA, USA; or anti-cyclin D1, ab16663, Abcam, Cambridge, UK); or anti-CD44, ab6124, Abcam, Cambridge, UK). The sections were washed for $15 \mathrm{~min}$ in PBS and incubated for $25 \mathrm{~min}$ at room temperature with a DAKO real EnVision detection system Peroxidase/DAB ${ }^{+}$(Dako, Glostrup, Denmark) according to the manufacturer's instructions. After washing in PBS, the peroxidase reaction was initiated by incubation with DAB (Dako, Glostrup, Denmark). Coverslips were mounted with Permount and evaluated under a light microscope. Image processing was performed using ImageJ software. For each sample, 10 representative images were taken with a $200 \times$ magnification. The percentage of stained area/total area was measured. Values from all consecutive images for each sample were averaged. For negative controls, a $1 \%$ nonimmune serum in PBS replaced the primary antibodies.

\subsection{Tissue Immunofluorescence and Confocal Laser Scanning Microscopy}

The protein expression of CD62-P (P-selectin), CD41 and CD44 was evaluated by indirect immunofluorescence and confocal microscopy analysis. Paraffin-embedded sections were permeabilized in a phosphate-buffered saline (PBS) with $0.05 \%$ TWEEN-20 for $5 \mathrm{~min}$, washed in PBS and then blocked with a $2 \%$ goat serum in PBS for $1 \mathrm{~h}$ at room temperature (RT). The sections were incubated overnight $(\mathrm{ON})$ in a humidified chamber at $4{ }^{\circ} \mathrm{C}$ with a primary antibody against CD62-P (1:500) (ab6632, Abcam, Cambridge, UK), CD41 (1:100) (ab63983, Abcam, Cambridge, UK) or CD44 (1:500) (ab6124, Abcam, Cambridge, UK) following incubation for $1 \mathrm{~h}$ with the appropriate secondary antibody (Alexa Fluor 488 goat anti-mouse, 1:200, A32723, Thermo Fisher Scientific; Alexa Fluor 555 goat anti-mouse, 1:200, A32727, Thermo Fisher Scientific). The sections were counterstained with To-Pro (Thermo Fisher Scientific), mounted in Fluoromount (Biomeda Corp, Foster City, CA, USA) and sealed with nail varnish. Negative controls were performed by omitting the primary antibodies. Specific fluorescence was acquired by a Leica TCS SP8 (Leica, Wetzlar, Germany) confocal laser-scanning microscope using a $630 \times$ objective lense and $5 \times$ optical zoom.

\subsection{Statistical Analysis}

All results are expressed as mean \pm SEM. Statistical analysis was executed using GraphPad Prism software (v5.0; GraphPad Software Inc., San Diego, CA, USA). Comparisons of the two groups were performed using the Student's $t$-test. A $p$ value of $<0.05$ was considered significant.

\section{Conclusions}

In conclusion, we show here the key role of platelets in intestinal tumor microenvironments. Platelets-cancer cells crosstalk via P-selectin is fundamental for tumor development. Indeed, platelets that do not adhere to cancer cells are not able to induce tumor growth. Moreover, in the absence of platelets-cancer cells' interaction, there is a reduction both in genetic and inflammatory-based colon cancer initiation and promotion. Our results support the hypothesis that a strategy aimed to inhibit platelets' adhesion to tumor cells are able to block tumor growth and could represent a novel therapeutic approach to colon cancer treatment.

Supplementary Materials: The following are available online at https:/ / www.mdpi.com/article/ 10.3390 / cancers13164243/s1, Figure S1: Platelets/intestinal cells crosstalk in human intestine. The protein expression of p-selectin and CD44 was investigated by immunofluorescence and confocal microscopy analysis in paraffin-embedded sections from normal portions of colon and colon adenocarcinoma. p-selectin in green and CD44 in red. Representative images are shown. Magnification $400 \times$, Figure S2: Gene expression analysis of Cyclin D1 and Pcna in HT-29 cells treated with P-sel ${ }^{+/+}$ platelets and HT-29 cells treated with $\mathrm{P}_{-} \mathrm{sel}^{-/-}$platelets. Cyclophilin was used as a housekeeping gene to normalize data. The results are expressed as mean \pm SEM. Statistical significance $(p<0.05)$ was assessed by T student's test ( $n=20$ tumors per group), Figure S3: Gene expression analysis of Il6 
in APCMin/P-sel ${ }^{-/-}$and APCMin mice. Cyclophilin was used as a housekeeping gene to normalize data. The results are expressed as mean \pm SEM. Statistical significance $(p<0.05)$ was assessed by T student's test ( $n=10$ mice per group), Figure S4: P-selectin KO mice are protected from chronic colitis-associated colorectal carcinogenesis. Gene expression analysis of Cyclin D1, Ccne1, Pten, Pcna and $\mathrm{Il} 6$ in $\mathrm{P}_{-} \mathrm{sel}^{-/-}$and P-sel ${ }^{+/+}$mice. Cyclophilin was used as a housekeeping gene to normalize data. The results are expressed as mean $\pm \operatorname{SEM}(n=10$ mice per group).

Author Contributions: M.C.: conceptualization, data curation, formal analysis, investigation, methodology, writing—original draft; E.P.: investigation, formal analysis; R.Z.: investigation, formal analysis; M.P.: investigation, formal analysis; C.P.: formal analysis; C.D.: formal analysis, data curation; A.S.: formal analysis, data curation; G.V.: formal analysis; G.I.: investigation; C.S.: supervision; A.M.: conceptualization, writing - review \& editing, project administration, funding acquisition, supervision. All authors have read and agreed to the published version of the manuscript.

Funding: This work was supported by: AIRC IG 201923239 to AM.

Institutional Review Board Statement: The Ethical Committee of the University of Bari and Fondazione "Mario Negri" Sud approved this experimental set-up, which also was certified by the Italian Ministry of Health in accordance with internationally accepted guidelines for animal care (protocol code 17198-X/10 date 7 March 2014).

Informed Consent Statement: Informed consent was obtained from all subjects involved in the study.

Data Availability Statement: The data presented in this study are all contained within this publication.

Acknowledgments: We thank G. Evangelista for providing the P-selectin ${ }^{-/}$mice.

Conflicts of Interest: The authors declare no conflict of interest.

\section{References}

1. Gay, L.J.; Felding-Habermann, B. Contribution of platelets to tumour metastasis. Nat. Rev. Cancer 2011, 11, 123-134. [CrossRef] [PubMed]

2. Davi, G.; Patrono, C. Platelet activation and atherothrombosis. N. Engl. J. Med. 2007, 357, 2482-2494. [CrossRef]

3. Lannan, K.L.; Sahler, J.; Kim, N.; Spinelli, S.L.; Maggirwar, S.B.; Garraud, O.; Cognasse, F.; Blumberg, N.; Phipps, R.P. Breaking the mold: Transcription factors in the anucleate platelet and platelet-derived microparticles. Front. Immunol. 2015, 6, 48. [CrossRef] [PubMed]

4. Denis, M.M.; Tolley, N.D.; Bunting, M.; Schwertz, H.; Jiang, H.; Lindemann, S.; Yost, C.C.; Rubner, F.J.; Albertine, K.H.; Swoboda, K.J.; et al. Escaping the nuclear confines: Signal-dependent pre-mRNA splicing in anucleate platelets. Cell 2005, 122, 379-391. [CrossRef]

5. Weyrich, A.S.; Schwertz, H.; Kraiss, L.W.; Zimmerman, G.A. Protein synthesis by platelets: Historical and new perspectives. J. Thromb. Haemost. 2009, 7, 241-246. [CrossRef]

6. Assoian, R.K.; Komoriya, A.; Meyers, C.A.; Miller, D.M.; Sporn, M.B. Transforming growth factor-beta in human platelets. Identification of a major storage site, purification, and characterization. J. Biol. Chem. 1983, 258, 7155-7160. [CrossRef]

7. Lordan, R.; Tsoupras, A.; Zabetakis, I. The Potential Role of Dietary Platelet-Activating Factor Inhibitors in Cancer Prevention and Treatment. Adv. Nutr. 2019, 10, 148-164. [CrossRef] [PubMed]

8. Nieswandt, B.; Hafner, M.; Echtenacher, B.; Mannel, D.N. Lysis of tumor cells by natural killer cells in mice is impeded by platelets. Cancer Res. 1999, 59, 1295-1300.

9. Palumbo, J.S.; Talmage, K.E.; Massari, J.V.; La Jeunesse, C.M.; Flick, M.J.; Kombrinck, K.W.; Jirouskova, M.; Degen, J.L. Platelets and fibrin(ogen) increase metastatic potential by impeding natural killer cell-mediated elimination of tumor cells. Blood 2005, 105, 178-185. [CrossRef] [PubMed]

10. Labelle, M.; Begum, S.; Hynes, R.O. Direct signaling between platelets and cancer cells induces an epithelial-mesenchymal-like transition and promotes metastasis. Cancer Cell 2011, 20, 576-590. [CrossRef] [PubMed]

11. Kalluri, R.; Weinberg, R.A. The basics of epithelial-mesenchymal transition. J. Clin. Investig. 2009, 119, 1420-1428. [CrossRef] [PubMed]

12. Furie, B.; Furie, B.C. The molecular basis of platelet and endothelial cell interaction with neutrophils and monocytes: Role of P-selectin and the P-selectin ligand, PSGL-1. Thromb. Haemost. 1995, 74, 224-227. [CrossRef] [PubMed]

13. Vestweber, D.; Blanks, J.E. Mechanisms that regulate the function of the selectins and their ligands. Physiol. Rev. 1999, 79, 181-213. [CrossRef] [PubMed]

14. Alves, C.S.; Burdick, M.M.; Thomas, S.N.; Pawar, P.; Konstantopoulos, K. The dual role of CD44 as a functional P-selectin ligand and fibrin receptor in colon carcinoma cell adhesion. Am. J. Physiol. Cell Physiol. 2008, 294, C907-C916. [CrossRef] 
15. Borsig, L.; Wong, R.; Hynes, R.O.; Varki, N.M.; Varki, A. Synergistic effects of L- and P-selectin in facilitating tumor metastasis can involve non-mucin ligands and implicate leukocytes as enhancers of metastasis. Proc. Natl. Acad. Sci. USA 2002, 99, $2193-2198$. [CrossRef]

16. Kim, Y.J.; Borsig, L.; Varki, N.M.; Varki, A. P-selectin deficiency attenuates tumor growth and metastasis. Proc. Natl. Acad. Sci. USA 1998, 95, 9325-9330. [CrossRef]

17. Chen, M.; Geng, J.G. P-selectin mediates adhesion of leukocytes, platelets, and cancer cells in inflammation, thrombosis, and cancer growth and metastasis. Arch. Immunol. Ther. Exp. 2006, 54, 75-84. [CrossRef]

18. Li, D.M.; Sun, H. TEP1, encoded by a candidate tumor suppressor locus, is a novel protein tyrosine phosphatase regulated by transforming growth factor beta. Cancer Res. 1997, 57, 2124-2129.

19. Popivanova, B.K.; Kitamura, K.; Wu, Y.; Kondo, T.; Kagaya, T.; Kaneko, S.; Oshima, M.; Fujii, C.; Mukaida, N. Blocking TNF-alpha in mice reduces colorectal carcinogenesis associated with chronic colitis. J. Clin. Investig. 2008, 118, 560-570. [CrossRef]

20. Lee, Y.J.; Lee, E.Y.; Choi, B.H.; Jang, H.; Myung, J.K.; You, H.J. The Role of Nuclear Receptor Subfamily 1 Group H Member 4 (NR1H4) in Colon Cancer Cell Survival through the Regulation of c-Myc Stability. Mol. Cells 2020, 43, 459-468. [CrossRef]

21. Smith, D.R.; Myint, T.; Goh, H.S. Over-expression of the c-myc proto-oncogene in colorectal carcinoma. Br. J. Cancer 1993, 68, 407-413. [CrossRef]

22. Joyce, J.A.; Pollard, J.W. Microenvironmental regulation of metastasis. Nat. Rev. Cancer 2009, 9, 239-252. [CrossRef]

23. Camerer, E.; Qazi, A.A.; Duong, D.N.; Cornelissen, I.; Advincula, R.; Coughlin, S.R. Platelets, protease-activated receptors, and fibrinogen in hematogenous metastasis. Blood 2004, 104, 397-401. [CrossRef] [PubMed]

24. Pearlstein, E.; Ambrogio, C.; Karpatkin, S. Effect of antiplatelet antibody on the development of pulmonary metastases following injection of CT26 colon adenocarcinoma, Lewis lung carcinoma, and B16 amelanotic melanoma tumor cells into mice. Cancer Res. 1984, 44, 3884-3887.

25. Rothwell, P.M.; Wilson, M.; Price, J.F.; Belch, J.F.; Meade, T.W.; Mehta, Z. Effect of daily aspirin on risk of cancer metastasis: A study of incident cancers during randomised controlled trials. Lancet 2012, 379, 1591-1601. [CrossRef]

26. Contursi, A.; Grande, R.; Dovizio, M.; Bruno, A.; Fullone, R.; Patrignani, P. Platelets in cancer development and diagnosis. Biochem. Soc. Trans. 2018, 46, 1517-1527. [CrossRef] [PubMed]

27. Dovizio, M.; Maier, T.J.; Alberti, S.; Di Francesco, L.; Marcantoni, E.; Munch, G.; John, C.M.; Suess, B.; Sgambato, A.; Steinhilber, D.; et al. Pharmacological inhibition of platelet-tumor cell cross-talk prevents platelet-induced overexpression of cyclooxygenase-2 in HT29 human colon carcinoma cells. Mol. Pharmacol. 2013, 84, 25-40. [CrossRef] [PubMed]

28. Guillem-Llobat, P.; Dovizio, M.; Bruno, A.; Ricciotti, E.; Cufino, V.; Sacco, A.; Grande, R.; Alberti, S.; Arena, V.; Cirillo, M.; et al. Aspirin prevents colorectal cancer metastasis in mice by splitting the crosstalk between platelets and tumor cells. Oncotarget 2016, 7, 32462-32477. [CrossRef] [PubMed]

29. Servais, L.; Wera, O.; Dibato Epoh, J.; Delierneux, C.; Bouznad, N.; Rahmouni, S.; Mazzucchelli, G.; Baiwir, D.; Delvenne, P.; Lancellotti, P.; et al. Platelets contribute to the initiation of colitis-associated cancer by promoting immunosuppression. J. Thromb. Haemost. 2018, 16, 762-777. [CrossRef] [PubMed]

30. Cole, B.F.; Logan, R.F.; Halabi, S.; Benamouzig, R.; Sandler, R.S.; Grainge, M.J.; Chaussade, S.; Baron, J.A. Aspirin for the chemoprevention of colorectal adenomas: Meta-analysis of the randomized trials. J. Natl. Cancer Inst. 2009, 101, $256-266$. [CrossRef]

31. Patrono, C.; Patrignani, P.; Garcia Rodriguez, L.A. Cyclooxygenase-selective inhibition of prostanoid formation: Transducing biochemical selectivity into clinical read-outs. J. Clin. Investig. 2001, 108, 7-13. [CrossRef]

32. Walz, G.; Aruffo, A.; Kolanus, W.; Bevilacqua, M.; Seed, B. Recognition by ELAM-1 of the sialyl-Lex determinant on myeloid and tumor cells. Science 1990, 250, 1132-1135. [CrossRef] [PubMed]

33. Aigner, S.; Ramos, C.L.; Hafezi-Moghadam, A.; Lawrence, M.B.; Friederichs, J.; Altevogt, P.; Ley, K. CD24 mediates rolling of breast carcinoma cells on P-selectin. FASEB J. 1998, 12, 1241-1251. [CrossRef]

34. Aigner, S.; Sthoeger, Z.M.; Fogel, M.; Weber, E.; Zarn, J.; Ruppert, M.; Zeller, Y.; Vestweber, D.; Stahel, R.; Sammar, M.; et al. CD24, a mucin-type glycoprotein, is a ligand for P-selectin on human tumor cells. Blood 1997, 89, 3385-3395. [CrossRef] [PubMed]

35. Hanley, W.D.; Napier, S.L.; Burdick, M.M.; Schnaar, R.L.; Sackstein, R.; Konstantopoulos, K. Variant isoforms of CD44 are P- and L-selectin ligands on colon carcinoma cells. FASEB J. 2006, 20, 337-339. [CrossRef] [PubMed]

36. Reyes-Reyes, M.E.; George, M.D.; Roberts, J.D.; Akiyama, S.K. P-selectin activates integrin-mediated colon carcinoma cell adhesion to fibronectin. Exp. Cell Res. 2006, 312, 4056-4069. [CrossRef] [PubMed]

37. Korniluk, A.; Kaminska, J.; Kiszlo, P.; Kemona, H.; Dymicka-Piekarska, V. Lectin adhesion proteins (P-, L- and E-selectins) as biomarkers in colorectal cancer. Biomarkers 2017, 22, 629-634. [CrossRef] [PubMed]

38. Matsui, Y.; Amano, H.; Ito, Y.; Eshima, K.; Suzuki, T.; Ogawa, F.; Iyoda, A.; Satoh, Y.; Kato, S.; Nakamura, M.; et al. Thromboxane $\mathrm{A}(2)$ receptor signaling facilitates tumor colonization through P-selectin-mediated interaction of tumor cells with platelets and endothelial cells. Cancer Sci. 2012, 103, 700-707. [CrossRef]

39. Qi, C.; Li, B.; Guo, S.; Wei, B.; Shao, C.; Li, J.; Yang, Y.; Zhang, Q.; Li, J.; He, X.; et al. P-Selectin-Mediated Adhesion between Platelets and Tumor Cells Promotes Intestinal Tumorigenesis in Apc(Min/+) Mice. Int. J. Biol. Sci. 2015, 11, 679-687. [CrossRef]

40. Qi, C.; Wei, B.; Zhou, W.; Yang, Y.; Li, B.; Guo, S.; Li, J.; Ye, J.; Li, J.; Zhang, Q.; et al. P-selectin-mediated platelet adhesion promotes tumor growth. Oncotarget 2015, 6, 6584-6596. [CrossRef] 
41. Wang, Q.; Li, Z.; Sun, L.; Chen, B.; Zhao, Y.; Shen, B.; Zhu, M.; Zhao, X.; Xu, C.; Wang, M.; et al. Platelets enhance the ability of bone-marrow mesenchymal stem cells to promote cancer metastasis. OncoTargets Ther. 2018, 11, 8251-8263. [CrossRef] [PubMed]

42. Mitrugno, A.; Sylman, J.L.; Ngo, A.T.; Pang, J.; Sears, R.C.; Williams, C.D.; McCarty, O.J. Aspirin therapy reduces the ability of platelets to promote colon and pancreatic cancer cell proliferation: Implications for the oncoprotein c-MYC. Am. J. Physiol. Cell Physiol. 2017, 312, C176-C189. [CrossRef] [PubMed]

43. Evangelista, V.; Manarini, S.; Sideri, R.; Rotondo, S.; Martelli, N.; Piccoli, A.; Totani, L.; Piccardoni, P.; Vestweber, D.; de Gaetano, G.; et al. Platelet/polymorphonuclear leukocyte interaction: P-selectin triggers protein-tyrosine phosphorylation-dependent CD11b/CD18 adhesion: Role of PSGL-1 as a signaling molecule. Blood 1999, 93, 876-885. [CrossRef]

44. Modica, S.; Murzilli, S.; Salvatore, L.; Schmidt, D.R.; Moschetta, A. Nuclear bile acid receptor FXR protects against intestinal tumorigenesis. Cancer Res. 2008, 68, 9589-9594. [CrossRef] [PubMed] 